\title{
S100A4 and ERBB2 as Co-Factors in Pancreatic Cancer
}

\author{
Anca Nastase ${ }^{1}$, Simona Dima ${ }^{1}$, Valeria Tica ${ }^{1}$, Raluca Florea ${ }^{1,2}$, Andrei Sorop ${ }^{1,2}$, Veronica Ilie ${ }^{1,2}$, \\ Mihai Eftimie $^{1}$, Liliana Paslaru', Vlad Herlea, ${ }^{3,4}$, Nicolae Bacalbasa ${ }^{5}$, Luminita Ivan ${ }^{6}$, Elena Uyy \\ Viorel Iulian Suica ${ }^{6}$, Felicia Antohe ${ }^{6}$, Iulia V Iancu ${ }^{7}$, Adriana Plesa ${ }^{7}$, Anca Botezatu ${ }^{7}$, Dan G Duda ${ }^{8}$, \\ Carmen C Diaconu ${ }^{7}$
}

\author{
1"Dan Setlacec" Center of General Surgery and Liver Transplantation, Fundeni Clinical Institute, \\ Bucharest, Romania \\ ${ }^{2}$ Faculty of Biology, University of Bucharest, Bucharest, Romania \\ ${ }^{3}$ Pathological Department, Fundeni Clinical Institute, Bucharest, Romania \\ ${ }^{4}$ Titu Maiorescu University, Faculty of Medicine, Bucharest, Romania \\ ${ }^{5}$ Carol Davila University of Medicine and Pharmacy, Bucharest, Romania \\ ${ }^{6}$ Institute of Cellular Biology and Pathology Nicolae Simionescu, Bucharest, Romania65 Stefan \\ ${ }^{7} \mathrm{~S}$ Nicolau Institute of Virology, Bucharest, Romania \\ ${ }^{8}$ Department of Radiation Oncology, Harvard Medical School, Boston, United States
}

\author{
Corresponding author: \\ Carmen C Diaconu, MD \\ S Nicolau Institute of Virology, \\ Bucharest, Romania \\ E-mail: ccdiaconu@yahoo.com
}

\section{ABSTRACT}

Background: Pancreatic ductal adenocarcinoma (PDAC) remains one of the most aggressive tumors with dismal prognosis and survival rates. Identifying early molecular diagnostic markers could contribute in improving survival in this intractable disease. Chromosomal rearrangements and altered expression of the gene have been implicated in PDAC progression to metastasis. S100A4 protein promotes invasion and metastasis by binding to several intracellular target proteins and modulating their function. ERBB2 is marker of poor prognosis in multiple cancer types. This study examined the potential clinical significance of S100A4 and ERBB2 expression in PDAC.

Materials and methods: Pairs of non-tumoral and tumoral tissues from a total of 73 patients with PDAC were included in our study to assess the gene expression of S100A4 by two-step qPCR using TaqMan hydrolysis probes. ERBB2 gene expression was assessed by SYBR Green chemistry. S100A4 protein expression was evaluated by immunohistochemistry.

Results: Gene expression of S100A4 was increased at advances stages of PDAC ( $p$-value $=$ 0.02 ) and with tumor grading. Kaplan-Meier survival distributions showed a significant difference in patient's survival outcome according to their S100A4 expression by immunohistochemistry (lower or higher than 10\%. p-value $=0.043$ ). Multi-variate Log Rank (MantelCox) test confirmed that resection type and S100A4 protein expression has a significant value in correlation with PDAC. Similarly, significant correlations were observed between ERBB2 gene expression and TNM tumor stage $(p$-value $=0.0048)$ and tumor grading $(p$-value $=0.048)$. Additional analysis showed a statistically significant correlation between S100A4 and ERBB2 gene expression levels ( $p$-value $=0.0094$ ).

Conclusions: Our results showed that both S100A4 and ERBB2 are associated with poor outcomes in PDAC, and might be valuable prognostic biomarkers.

Key words: PDAC, S100A4, ERBB2

Received: 29.11.2016 Accepted: 15.12 .2016

Copyright (๑) Celsius Publishing House 


\section{INTRODUCTION}

Pancreatic ductal adenocarcinoma (PDAC) is the fourth most lethal cancer (1) and is expected to become one of the top three cancer killers among lung and liver cancer by 2030 in US only (2). PDAC is responsible for $7 \%$ of all cancer-related deaths in both men and women, as its treatment remains a major challenge despite multi-modality approaches. The five-year survival is dismal due to late diagnostic, presence of metastasis at the time of diagnostic and resistance of cancer cell to chemotherapeutics. Improving detection and prognostication could decrease the morbidity caused by this disease and increase survival.

The majority of all exocrine pancreatic tumors are pancreatic ductal adenocarcinoma (PDAC). Most of PDAC cases (60-70\%) occurs preponderantly in head of the pancreas (3) and are characterized by the presence of a dense stroma made of fibroblast and inflammatory cells termed desmoplasia (4). In this hypoxic microenvironment thus created, the stroma is the component that is believed to supports tumor growth and metastatic spread $(5,6)$.

S100A4 is a pro-metastatic gene and more recent studies indicated that S100A4 could be a key factor in promoting EMT (7) we choose to study its role in PDAC tissue patients and to investigate its correlation with clinico-pathologic features.

Also, in an orthotopic model of bladder cancer, the overexpression of S100A4 lead to development of lymph nodes and lung metastasis (8). Moreover, transfection studies using different cell systems have shown that S100A4 is involved in cell motility $(9,10)$.

Overexpression of ERBB2, which is one of the four members of EGFR family (11) has been reported in 7$61 \%$ of the PDACs $(12,13,14,15,16)$. In addition to being an oncogenic driver, the ERBB2 receptor may also mediate intracellular pathways related to chemoresistance in PDAC (17).

In addition, American Society of Clinical Oncology (ASCO) highlights that S100A4 is one potential biomarker, which has the ability to predict patient survival after surgery for PDAC (18). Transcription of the prometastatic S100A4 gene is controlled by both positive and negative regulatory elements located within the first intron, which bind several transcription factors. ERBB2 directs S100A4 expression via a signaling network that includes PI3K, AKT1 and ERK1/2. Activated AKT1 phosphorylates p21Cip/WAF1 cell cycle inhibitor resulting in increased cell proliferation. S100A4 promoter contains an ERBB2 response element (19).
The aim of this study was to investigate S100A4 and ERBB2 gene expression levels as well as the protein level of S100A4 as potential regulatory factors in PDAC oncogenesis.

\section{MATERIAL AND METHODS}

\section{Patients' selection and sample collection}

The study prospectively enrolled patients diagnosed with PDAC and scheduled for curative surgery of their disease were prospectively included in the present study. All patients signed an informed written consent prior to samples collection. During the surgical intervention, a sample or normal (non-tumoral) and tumoral tissue were collected in RNALater (Sigma, St. Louis, MO) for RNA and DNA extractions, kept at $4^{\circ} \mathrm{C}$ for 24 hours and then snap-frozen in liquid nitrogen.

\section{RNA extractions}

Total RNA was isolated from normal and tumoral tissue samples by means of TRI reagent (Sigma, St. Louis, $\mathrm{MO})$ according to the manufacturer's instructions, followed by further purification using RNeasy Mini Kit (QIAGEN, Valencia, CA). The quantity and quality of the total RNA were assessed by spectrophotometry (Nano Drop 1000; Thermo Scientific, Arlington, TX) and by lab-on-a-chip Agilent 2100 technology (Agilent Technology, Santa Clara, CA). Samples with a 260:280 $\mathrm{nm}$ ratio greater than 1.8 , a $28 \mathrm{~S}: 18 \mathrm{~S}$ ratio greater than 1.5 and an RNA integrity number greater than 7 were used for gene expression profiling of S100A4.

\section{Real-time qPCR}

Gene expression of S100A4 wad determined by using hydrolysis probes labeled with 6-carboxyfluorescein (Hs00243202_m1) using $18 \mathrm{~S}$ as a reference gene (Hs99999901_s1) while gene expression for ERBB2 was determined with FastStart Universal SYBR Green Master (ROX) (Roche Molecular Biochemicals, Mannheim, Germany) having GAPDH as housekeeping gene. The GAPDH and ERBB2 sequences used were:

GAPDH: F: 5'-CCATCTTCCAGGAGCGAGATCCCT-3', R: 5'-TGAGCCCCAGCCTTCTCCATGGT-3', ERBB2: F: 5'-TAGGGTTAAGGGAAGGCGGA-3', R: 5'GTGGTACTTCAATTGCGACTCA-3'.

The final DNA concentration was $10 \mathrm{ng} / \mu \mathrm{l}$ in a final volume of $25 \mu \mathrm{l}$. For all genes fold changes were determined in tumoral tissues compared with paired normal tissue. Data were analyzed either with SDS 1.4 software (for S100A4) or manually (ERBB2) and the fold changes were determined by using the comparative $\mathrm{Ct}$ method $\left[2^{\wedge}(\right.$-delta delta $\left.\mathrm{Ct})\right]$. 


\section{Immunohistochemistry}

Paraffin tissue sections were adjusted to the size of $4 \mathrm{~mm}$ and were subsequently deparaffined and hydrated in xylene and graded ethanol. Epitopes were revealed by $10 \mathrm{mM}$ citrate buffer with a $\mathrm{pH} 6.0$ and $1 \mathrm{mM}$ EDTA. For staining we used an anti-human S100A4 polyclonal rabbit antibody (Dako) at a final dilution of 1:150. The staining of S100A4 was evaluated as either low $(\leq 10 \%)$ or high $(>10 \%)$.

\section{Statistical analysis}

To examine differences in the clinical data between patients and controls, either the Student's t-test (when values were normally distributed) or the non-parametric Mann-Whitney test (when the distribution normality test failed) were used. For subgroup analyses and the comparison of genes expression levels Kruskal-Wallis test followed by Dunn's Multiple Comparison post hoc test was used. A p-value $<0.05$ was considered statistically significant. The median and interquartile ranges are reported unless stated otherwise. All calculations were performed using GraphPad Prism version 5.02 for Windows (GraphPad Software, San Diego, CA).

\section{RESULTS}

\section{Patient's characteristics}

A total number of 73 patients were included in our study. The available clinical and pathological features are shown in table 1.

The patients were relatively equal distributed between gender sex ratio male:female - 56.2:43.8. The median age at the surgery was 60 years old. Most of the patients (45.2\%) were diagnosed in IIB stage of disease and patients presented in a higher percentage (52\%) G1 differentiation degree.

Fifty-seven percent of patients presented lymph node metastasis, and $46.6 \%$ received preoperative chemotherapy. Median tumor size was $3 \mathrm{~cm}$ and $80.8 \%$ of patients underwent $\mathrm{R} 0$ resection type.

\section{S100A4 gene expression in PDAC tissues}

The gene expression analysis was done using the formula $2^{-\Delta \Delta c t}$. We performed a double normalization. First compared to the housekeeping gene and then with the paired normal samples.

We observed an overexpression of S100A4 in tumor tissue compared to normal tissues. Further analysis of S100A4 showed an increase trend of gene expression of
Table 1 - Clinicopathological features of the study group

\begin{tabular}{|c|c|c|}
\hline Parameters & N & $\%$ \\
\hline \multicolumn{3}{|l|}{ Gender } \\
\hline$F$ & 32 & 43.8 \\
\hline$M$ & 41 & 56.2 \\
\hline \multicolumn{3}{|l|}{ Age at surgery } \\
\hline Average $\pm S D$ & $61 \pm 9$ & \\
\hline Median (range) & $60[35-77]$ & \\
\hline \multicolumn{3}{|l|}{ TNM stage } \\
\hline I & 19 & 26 \\
\hline$\| \mathrm{A}$ & 9 & 12.3 \\
\hline$\| B$ & 33 & 45.2 \\
\hline $\mathrm{III}+\mathrm{IV}$ & 11 & 15.1 \\
\hline unknown & 1 & 1.4 \\
\hline \multicolumn{3}{|l|}{ Differentiation degree } \\
\hline G1 & 38 & 52 \\
\hline G2 & 28 & 38.5 \\
\hline G3 & 7 & 9.5 \\
\hline \multicolumn{3}{|l|}{ pN } \\
\hline NO & 29 & 39.7 \\
\hline N1 & 42 & 57.5 \\
\hline unknown & 2 & 2.8 \\
\hline \multicolumn{3}{|l|}{ LNR } \\
\hline$<0.16$ & 43 & 58.9 \\
\hline$\geq 0.16$ & 26 & 35.6 \\
\hline unknown & 4 & 5.5 \\
\hline \multicolumn{3}{|l|}{ Preoperative chemotherapy } \\
\hline Yes & 34 & 46.6 \\
\hline No & 15 & 20.5 \\
\hline unknown & 24 & 32.9 \\
\hline \multicolumn{3}{|l|}{ Tumor diameter } \\
\hline Average $\pm S D$ & $2.89 \pm 1.4$ & \\
\hline Median (range) & $3[0.3-8]$ & \\
\hline \multicolumn{3}{|l|}{ Resection type } \\
\hline RO & 59 & 80.8 \\
\hline R1 & 3 & 4.1 \\
\hline other & 2 & 2.7 \\
\hline unknown & 9 & 12.3 \\
\hline \multicolumn{3}{|l|}{ Survival (months) } \\
\hline Average $\pm S D$ & $15.78 \pm 17.69$ & \\
\hline Median (range) & $10[0-104]$ & \\
\hline
\end{tabular}

S100A4 with increased tumor stage, tumor differentiation degree, number of lymph nodes as well as with the lymph node ratio (table 2).

We found that S100A4 gene expression associated with the severity of disease ( $p=0.02$ for tumor staging) and with the degree of tumor differentiation (fig. 1). Correlations between subgroups of patients based on clinicopathological parameters were studied with longrank test. The results of the univariate analysis are present in table 3.

These parameters were further analyzed for correlations with outcome by Log Rank Mantel-Cox in a multivariate analysis. The resection type and S100A4 protein expression were the only factors that showed a significant correlation with survival (table 4). 
Table 2 - $\log _{10} n$-fold gene expression of S100A4 in patient's groups

\begin{tabular}{|c|c|c|}
\hline Parametes & $\begin{array}{l}\text { S100A4 median } \\
\text { (range) }\end{array}$ & $P$ value \\
\hline \multicolumn{3}{|l|}{ Gender } \\
\hline M & $0.75[-0.39-2.58]$ & 0.64 \\
\hline $\mathrm{F}$ & $0.81[-0.65-2.68]$ & \\
\hline \multicolumn{3}{|l|}{ TNM stage } \\
\hline 1 & $0.59[-0.65-2.58]$ & 0.02 \\
\hline$\|$ & $0.84[0.25-2.17]$ & \\
\hline III, IV & $1.59[0.87-2.68]$ & \\
\hline \multicolumn{3}{|c|}{ Tumor differentiation degree } \\
\hline G1 & $0.74[-0.65-2.68]$ & 0.5 \\
\hline G2, G3 & $0.81[-0.33-2.58]$ & \\
\hline \multicolumn{3}{|l|}{$\mathrm{pN}$} \\
\hline pNO & $0.62[0-0.65-2.68]$ & 0.09 \\
\hline pN1 & $0.91[-0.31-2.17]$ & \\
\hline \multicolumn{3}{|l|}{$\mathrm{LNR}^{*}$} \\
\hline$<0.16$ & $0.74[-0.65-2.68]$ & 0.21 \\
\hline$\geq 0.16$ & $0.91[-0.32-2.17]$ & \\
\hline \multicolumn{3}{|l|}{ Diabetes } \\
\hline Yes & $0.66[-0.33-2.13]$ & 0.61 \\
\hline No & $0.80[-0.65-2.68]$ & \\
\hline
\end{tabular}

* the 0.16 cut-off represents the arithmetic mean of LNR for the total patients group included in the study
Table 3 - Results of the univariate Kaplan Meier analysis

\begin{tabular}{|c|c|}
\hline \multirow{2}{*}{\multicolumn{2}{|c|}{$\begin{array}{l}\text { Parameters } \\
\mathrm{T} \text { (tumor extension) }\end{array}$}} \\
\hline & \\
\hline T3\&T4 & 0.18 \\
\hline \multicolumn{2}{|l|}{ N (lymph node invasion) } \\
\hline N1 & 0.28 \\
\hline \multicolumn{2}{|l|}{ M (metastasis) } \\
\hline \multicolumn{2}{|l|}{ M0 } \\
\hline M1 & 0.08 \\
\hline \multicolumn{2}{|l|}{ TNM stage } \\
\hline $\begin{array}{l}\text { IIB } \\
\text { III\&IV }\end{array}$ & 0.21 \\
\hline \multicolumn{2}{|l|}{ Tumor differentiation } \\
\hline \multicolumn{2}{|l|}{ G1. G2 } \\
\hline G3 & 0.46 \\
\hline \multicolumn{2}{|l|}{ LNR } \\
\hline LNR (cut-off 0) & 0.22 \\
\hline LNR (cut-off 0.16) & 0.06 \\
\hline \multicolumn{2}{|l|}{ Resection type } \\
\hline \multicolumn{2}{|l|}{ Yes } \\
\hline No & 0.17 \\
\hline \multicolumn{2}{|l|}{ RO } \\
\hline R1 & 0.003 \\
\hline \multicolumn{2}{|l|}{ CA19-9 } \\
\hline \multicolumn{2}{|l|}{$\leq 1000$} \\
\hline$>1000$ & 0.05 \\
\hline \multicolumn{2}{|l|}{$\begin{array}{l}\text { S100A4 protein expression } \\
\leq 10 \%\end{array}$} \\
\hline$>10 \%$ & 0.043 \\
\hline
\end{tabular}
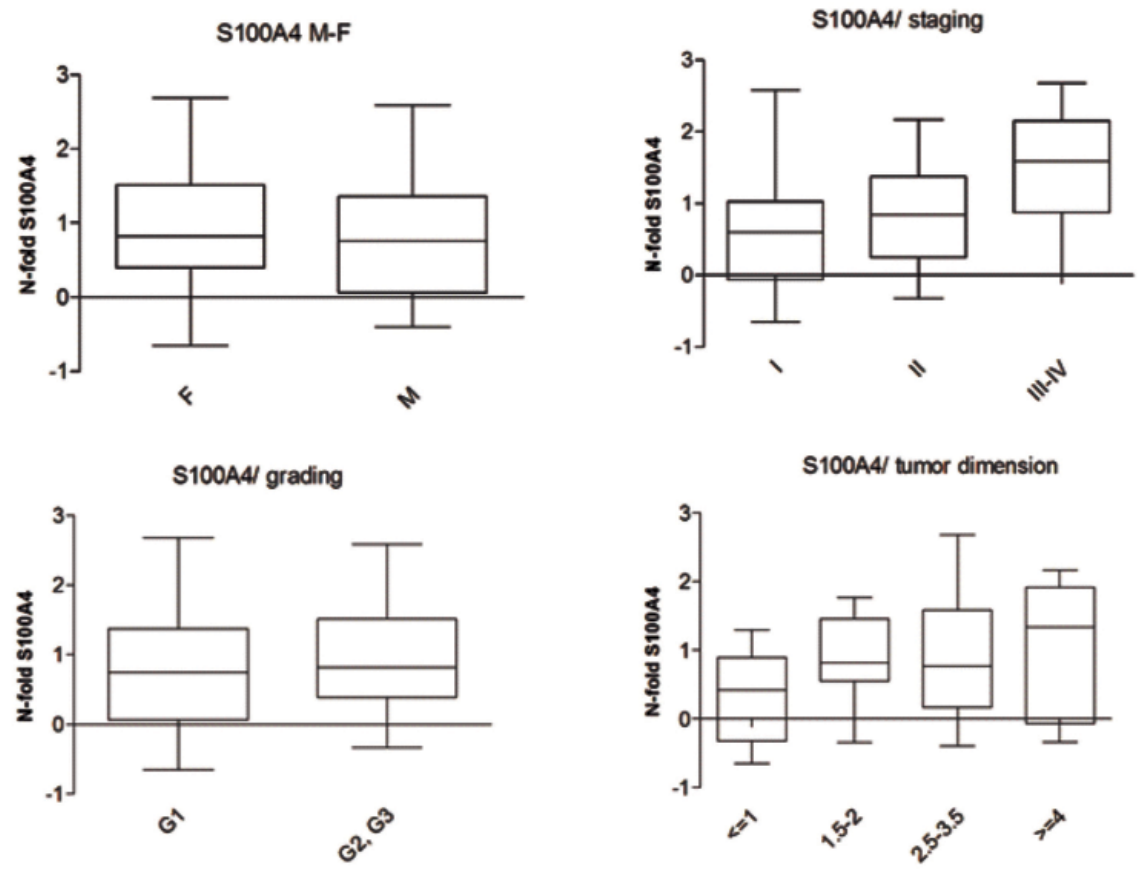

Figure 1 - S100A4 gene expression levels based on gender, staging, tumor grading and tumor size 
Table 4 - Results of the multivariate Kaplan Meier analysis

\begin{tabular}{lccccc}
\hline Parameter & \multicolumn{3}{c}{} & \multicolumn{2}{c}{ 95\% Cl } \\
& Sig. & Exp(B) & min. & max. \\
\hline LNR & 0.42 & & & \\
\hline LNR (cut-off 0) & 0.86 & 0.90 & 0.28 & 2.86 \\
\hline LNR (cut-off 0.16) & 0.20 & 1.78 & 0.73 & 4.32 \\
\hline Resection type (R0/R1) & 0.007 & 33.00 & 2.58 & 421.21 \\
\hline Metastasis (M0/M1) & 0.70 & 1.38 & 0.25 & 7.65 \\
\hline CA19-9 (cut-off 1000) & 0.11 & 2.83 & 0.78 & 10.19 \\
\hline Protein expression S100A4 & 0.05 & 3.56 & 0.96 & 13.18 \\
\hline
\end{tabular}

\section{Detection of S100A4 protein expression in PDAC tissues by immunohistochemistry}

Immunohistochemistry for S100A4 showed a cytoplasmic staining of the cells (fig. 1).

Analysis of the correlation between S100A4 immunostaining and survival showed a significant difference between patients with high S100A4 protein expression (>10\%) compared with low S100A4 protein expression ( $\leq 10 \%$ ) [Log. Rank (Mantel-Cox) $p=0.043$ ] (fig. 2). The median overall survival (OS) for patients with low expression ( $\leq 10 \%$ ) was $25 \pm 12.55$ months, which was significantly longer than in patients with high expression $(>10 \%)-12 \pm 1.89$ months $(p=0.043$, fig. 3$)$.

\section{ERBB2 gene expression in PDAC tissues}

We next evaluated the ERBB2 gene expression in our study group. The statistical analysis with clinicopathological features is presented in table 5 .

We found that the ERBB2 gene expression was significantly associated in III and IV disease stage $(p=0.0048)$, and with tumor differentiation grade $(\mathrm{p}=0.0480)$ (fig. 4).

The highest ERBB2 gene expression was not significantly correlated with tumor dimension. However, an increased expression was observed in tumors larger than $4 \mathrm{~cm}$.

Analysis of the correlation between ERBB2 gene expression and survival showed a difference (but not significant) between patients with high ERBB2 gene expression ( $>2$-fold) compared with low ERBB2 gene expression ( $<2$-fold), when we refer to normal adjacent tissue.

Kaplan-Meier analysis of OS distribution showed that the patients with the ERBB2 gene expression of $\mathrm{n}$-fold $>2$ had a median OS of 21 months, which was higher than patients with ERBB2 $\mathrm{n}$-fold $<2$, who had a median OS of 17 months (fig. 5).

The higher ERBB2 expression level the decreased survival period of time was observed, therefore an

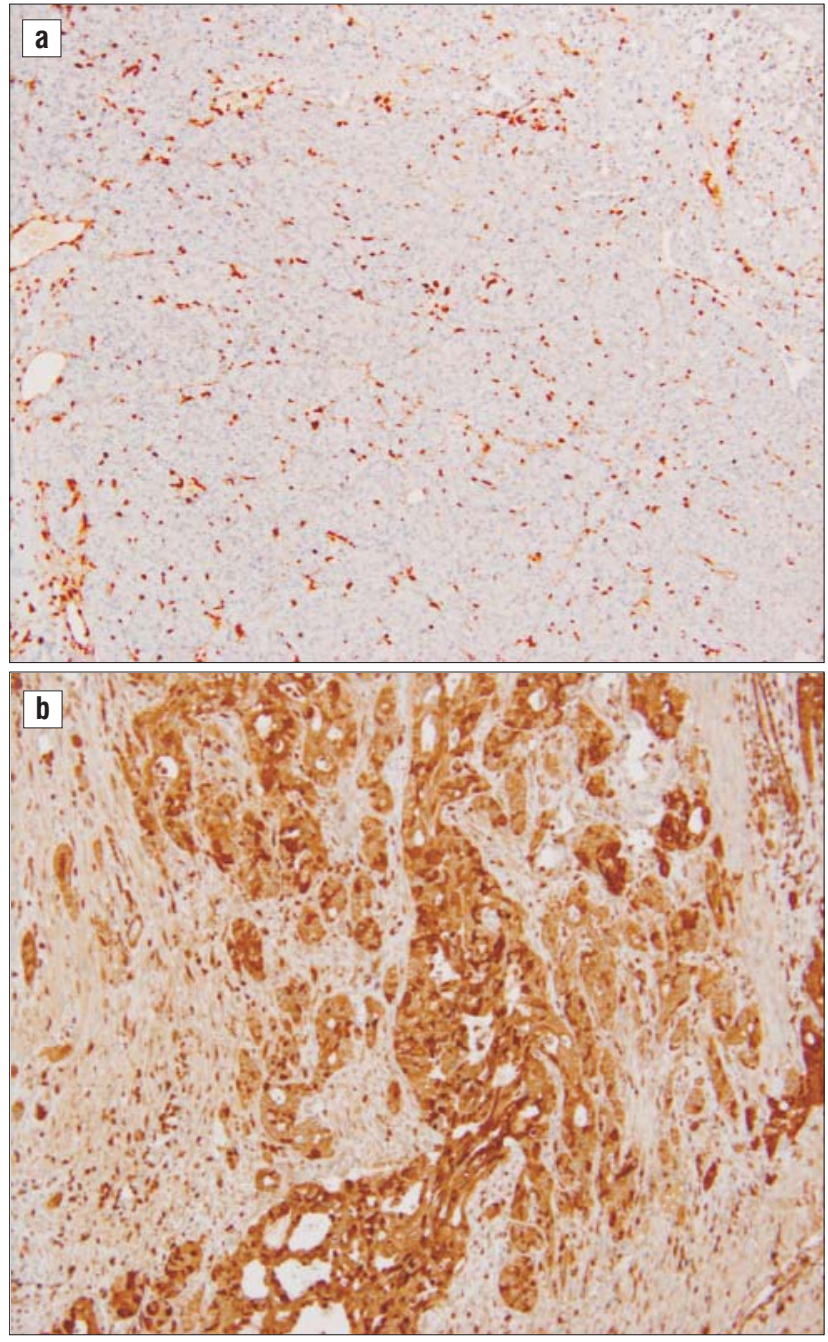

Figure 2 - Immunohistochemistry of S100A4 in (a) normal tissue and (b) tumoral tissue

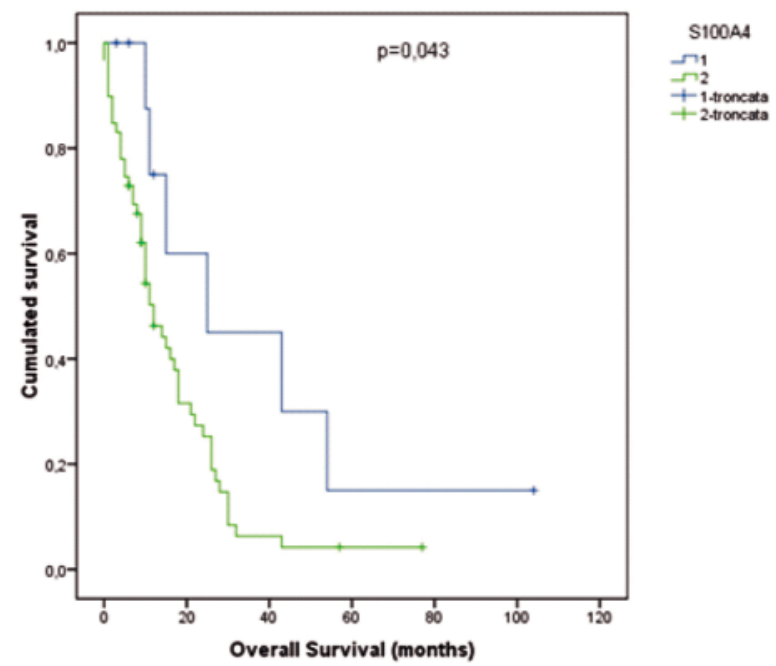

Figure 3 - Kaplan-Meier survival distributions for PDAC patients based on S100A4 staining; 1 - the group of patients with low S100A4 expression. 2 - the group of patients with high S100A4 expression 
Table 5 - Gene expression of ERBB2 and association with PDAC patients' characteristics

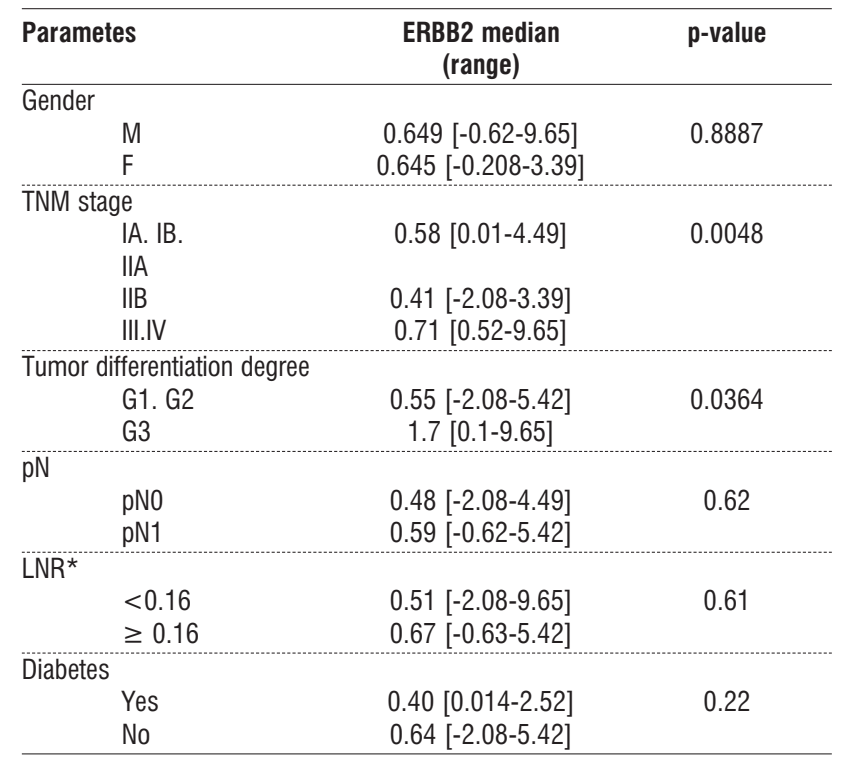

increased ERBB2 expression level can be correlated with poor prognostic.

We used Spearman correlation to evaluate a possible association between the factors (S100A4 and ERBB2). The analysis showed that these two tissue biomarkers are significantly inversely correlated in PDAC ( $r 2=-0.332595 \% \mathrm{Cl}: 0.5463,-0.07818, \mathrm{p}=0.0094)$ (fig. 6).

\section{DISCUSSION}

At the time of diagnosis, the vast majority of PDAC patients present with an advanced tumor stage. Because of the late diagnosis, the curative interventions are very limited, which leads to a poor prognosis and a dismal overall survival for these patients (less than $5 \%$ at 5 years). This study examined two candidate biomarkers - S100A4 and ERBB2 - for estimating more accurately the prognosis of surgically resected PDAC patients.

\section{ERBB2 M-F}

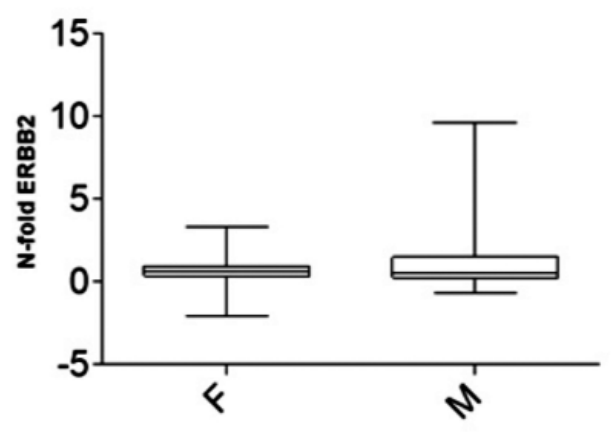

ERBB2/grading

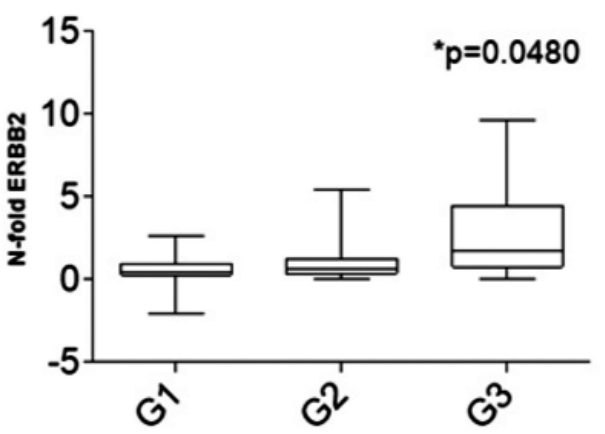

ERBB2/staging

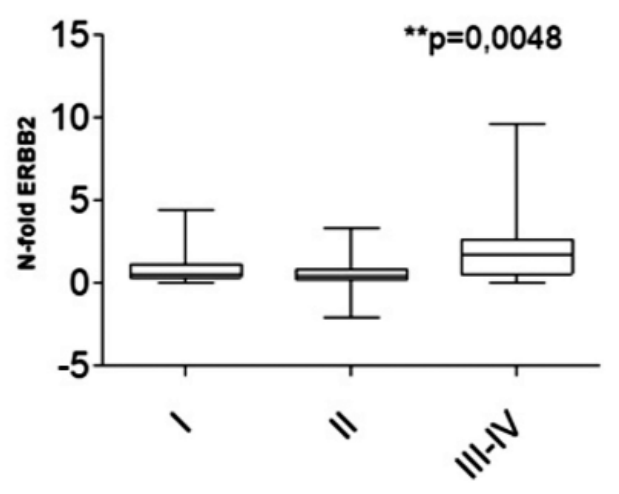

ERBB2/ tumor dimension

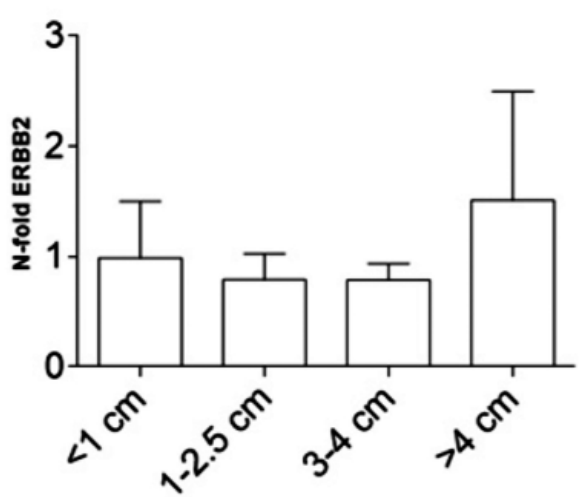

Figure 4 - The ERBB2 gene expression levels based on gender, tumor differentiation grade and tumor size for investigated patients 


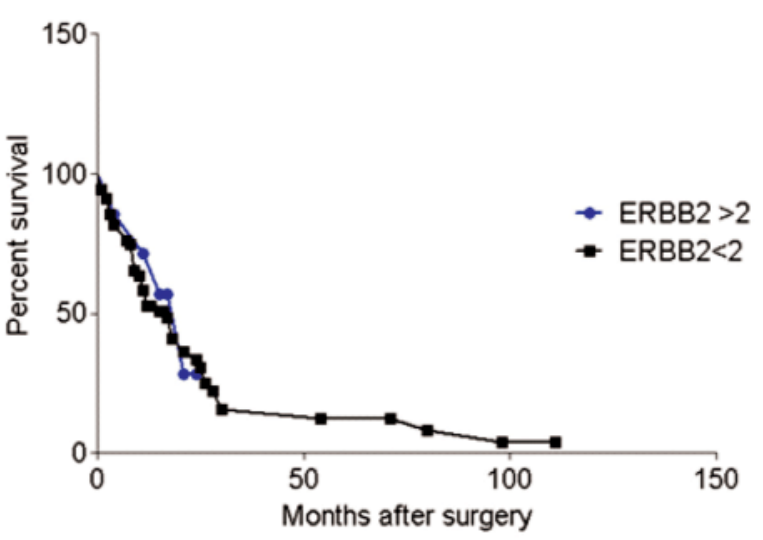

Figure 5 - Kaplan-Meier survival curve for patients based on ERBB2 gene expression

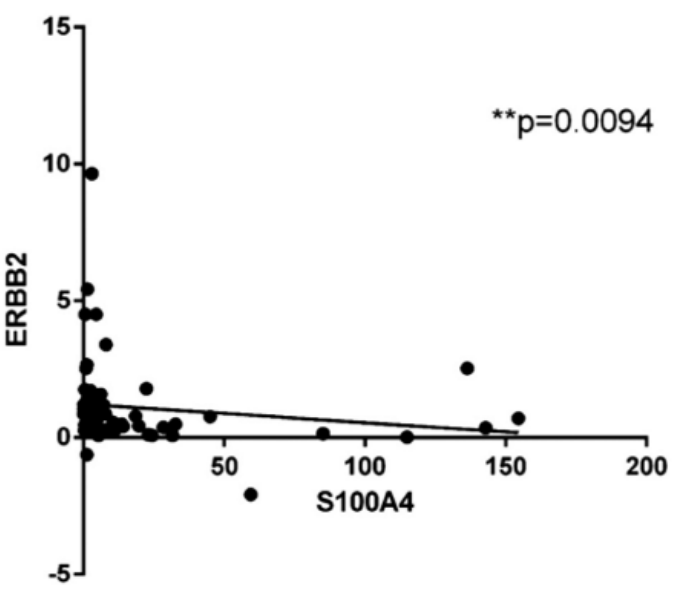

Figure 6 - Correlation between S100A4 and ERBB2 gene expression for the investigated patients
Our data indicate that S100A4 may be a valuable prognostic biomarker, consistent with its important roles in tumor progression. We observed an increased gene expression along with increased tumor stage, tumor differentiation degree, number of lymph nodes as well as with the lymph node ratio (LNR). Furthermore, high protein levels of S100A4 determined by immunohistochemistry correlated with poor OS in the PDAC patients. These results are in line with prior reports of S100A4 overexpression in PDAC and its correlation with tumor invasiveness and size, disease stage and poor prognosis $(20,21)$.

It has been shown that S100A4 synergize with ERBB2 in the development of metastatic breast cancer (22), and ERBB2 act signaling via PI3K and ERK1/2 to activate S100A4 expression, by enhancing transcription. The expression of ERBB2 and S100A4 are concordant, also in primary human medulloblastoma. Therefore, suggesting that ERBB2 may promote the metastasis. On the other hand, the S100A4 promoter presents response element located between bp -1487 and -1099, indicating that ERBB2 may also, controls the S100A4 gene expression (23).

The mechanism that involves ERBB2 in metastasis remains to be elucidated. Its overexpression was already determined to be correlated with drug resistance and decrease patient survival time (24).

Moreover, in pancreatic cancer it is well known that a significant number of cases presents an increased level of expression of ERBB2/HER2 and this is linked with a poor prognosis and resistance to therapy $(25,26)$.

\section{CONCLUSIONS}

In our study both S100A4 and ERBB2 showed statistically significant correlation with clinicopathologic features of the studied patients` group.

Aberrant expression of S100A4 and ERBB2 at both gene and protein level stratifies PDAC patients in good and poor prognostic. Further studies in a bigger lot of patients can clarify the involvement of S100A4 in PDAC progression as well as the contribution of ERBB2 in activation of S100A4, which might have further clinical implications and the potential to improve patient selection.

\section{Acknowledgements}

This study was supported by grant PN-II-PT-PCCA2011-90 from National Authority for Scientific Research.

\section{REFERENCES}

1. Siegel R1, Ma J, Zou Z, Jemal A. Cancer statistics. 2014. CA Cancer J Clin. 2014 Jan-Feb;64(1):9-29. doi: 10.3322/caac.21208. Epub 2014 Jan 7.

2. Scientific framework for recalcitrant cancers 2013. In: One Hundred Twelfth Congress of the United States of America; 2012; Washington. DC. HR 4310-13:1083

3. Bosman FT, Carneiro F, Hruban R H, Theise N. WHO classification of tumours of the digestive system, fourth edition. France: IARC; 2010

4. Apte MV, Park S, Phillips PA, Santucci N, Goldstein D, Kumar RK, et al. Desmoplastic reaction in pancreatic cancer: role of pancreatic stellate cells. Pancreas. 2004 0ct;29(3):179-87.

5. Erez N, Truitt M, Olson P, Arron ST, Hanahan D. Cancer-Associated Fibroblasts Are Activated in Incipient Neoplasia to Orchestrate TumorPromoting Inflammation in an NF-kappaB-Dependent Manner. Cancer Cell. 2010 Feb 17;17(2):135-47. doi: 10.1016/j.ccr.2009.12.041. Epub 2010 Feb 4. 
6. Straussman R, Morikawa T, Shee K, Barzily-Rokni M, Qian ZR, Du J, et al. Tumour micro-environment elicits innate resistance to RAF inhibitors through HGF secretion. Nature. 2012 Jul 26;487(7408):5004. doi: 10.1038/nature11183.

7. Xu X, Su B, Xie C, Wei S, Zhou Y, Liu H, et al. Sonic hedgehog-Gli1 signaling pathway regulates the epithelial mesenchymal transition (EMT) by mediating a new target gene. S100A4. in pancreatic cancer cells. PLoS One. 2014 Jul 29;9(7):e96441. doi: 10.1371/journal.pone. 0096441. eCollection 2014.

8. Levett D, Flecknell PA, Rudland PS, Barraclough R, Neal DE, Mellon JK, et al. Transfection of S100A4 produces metastatic variants of an orthotopic model of bladder cancer. Am J Pathol. 2002 Feb;160(2):693-700.

9. Stein U, Arlt F, Walther W, Smith J, Waldman T, Harris ED, et al. The metastasis-associated gene S100A4 is a novel target of $\beta$-catenin $/ \mathrm{T}$ cell factor signaling in colon cancer. Gastroenterology. 2006 Nov;131(5):1486-500. Epub 2006 Aug 22.

10. Kikuchi N, Horiuchi A, Osada R, Imai T, Wang C, Chen X, et al. Nuclear expression of S100A4 is associated with aggressive behavior of epithelial ovarian carcinoma: an important autocrine/paracrine factor in tumor progression. Cancer Sci. 2006 Oct;97(10):1061-9.

11. Wolle D, Lee SJ, Li Z, Litan A, Barwe SP, Langhans SA. Inhibition of epidermal growth factor signaling by the cardiac glycoside ouabain in medulloblastoma. Cancer Med. 2014 0ct;3(5):1146-58. doi: 10.1002 cam4.314. Epub 2014 Jul 23.

12. Omar N, Yan B, Salto-Tellez M, HER2: An emerging biomarker in nonbreast and nongastric cancers. Pathogenesis, 2015;2(3):1-9.

13. Harder J, Ihorst G, Heinemann V, Hofheinz R, Moehler M, Buechler P, et al. Multicentre phase II trial of trastuzumab and capecitabine in patients with HER2 overexpressing metastatic pancreatic cancer. $\mathrm{Br}$ Cancer. 2012 Mar 13;106(6):1033-8. doi: 10.1038/bjc.2012.18. Epub 2012 Feb 28.

14. Komoto M, Nakata B, Amano R, Yamada N, Yashiro M, Ohira M, et al. HER2 overexpression correlates with survival after curative resection of pancreatic cancer. Cancer Sci. 2009 Jul;100(7):1243-7. doi: 10.1111/j.1349-7006.2009.01176.x. Epub 2009 Apr 21

15. Stoecklein NH, Luebke AM, Erbersdobler A, Knoefel WT, Schraut W, Verde PE, et al. Copy number of chromosome 17 but not HER2 amplification predicts clinical outcome of patients with pancreatic ductal adenocarcinoma. J Clin Oncol. 2004 Dec 1;22(23):4737-45

16. Sharif S, Ramanathan RK, Potter D, Cieply K, Krasinskas AM. HER2 gene amplification and chromosome 17 copy number do not predict survival of patients with resected pancreatic adenocarcinoma. Dig Dis Sci. 2008 Nov;53(11):3026-32. doi: 10.1007/s10620-008-0267-1. Epub 2008 May 8.

17. Chou A, Waddell N, Cowley MJ, Gill AJ, Chang DK, Patch AM, et al. Clinical and molecular characterization of HER2 amplified-pancreatic cancer. Genome Med. 2013 Aug 31;5(8):78. doi: 10.1186/gm482. eCollection 2013.

18. Skrypek N, Vasseur R, Vincent A, Duchêne B, Van Seuningen I, Jonckheere $\mathrm{N}$. The oncogenic receptor ErbB2 modulates gemcitabine and irinotecan/SN-38 chemoresistance of human pancreatic cancer cells via hCNT1 transporter and multidrug-resistance associated protein MRP-2. Oncotarget. 2015 May 10;6(13):10853-67.

19. Nguyen NQ, Ruszkiewicz A, Chang D, Bambrick J, Biankin AV, Royal Adelaide Hospital, Adelaide, Australia; Wolfson Wohl Cancer Research Centre, Glasgow, Scotland. Biomarker assessment from EUS-guided biopsy to predict outcomes and treatment in pancreatic cancer. J Clin Oncol. 2014;32 suppl 3: abstr 182.

20. Incassati A, Chandramouli A, Eelkema R, Cowin P. Key signaling nodes in mammary gland development and cancer: $\beta$-catenin. Breast Cancer Res. 2010;12(6):213. doi:10.1186/bcr2723

21. Tsukamoto N, Egawa S, Akada M, Abe K, Saiki Y, Kaneko N, et al. The expression of S100A4 in human pancreatic cancer is associated with invasion. Pancreas. 2013 Aug:42(6):1027-33.

22. Ai KX, Lu LY, Huang XY, Chen W, Zhang HZ.Prognostic significance of S100A4 and vascular endothelial growth factor expression in pancreatic cancer. World J Gastroenterol. 2008 Mar 28;14(12): $1931-5$.

23. Davies BR, O'Donnell M., Durkan GC, Rudland PS, Barraclough R, Neal DE, et al. Expression of S100A4 protein is associated with metastasis and reduced survival in human bladder cancer. J Pathol. 2002 Mar;196(3):292-9.

24. Hernan R, Fasheh R, Calabrese C, Frank AJ, Maclean KH, Allard D, et al. ERBB2 Up-Regulates S100A4 and Several other Prometastatic Genes in Medulloblastoma. Cancer Res. 2003 Jan 1;63(1):140-8

25. Klapper LN, Kirschbaum MH, Sela M, Yarden Y. Biochemical and clinical implications of the ErbB/HER signaling network of growth factor receptors. Adv Cancer Res. 2000;77:25-79.

26. Safran H, Steinhoff M, Mangray S, Rathore R, King TC, Chai L, et al. Overexpression of the HER-2/neu oncogene in pancreatic adenocarcinoma. Am J Clin Oncol. 2001 Oct;24(5):496-9. 